\title{
0859. Altered expression of the bone morphogenetic antagonists in the bleomycin model of acute lung injury
}

\author{
N Murphy ${ }^{1,2^{*}}$, S Coyle Rowan ${ }^{3}$, S Frohlich ${ }^{2,4}$, P McLoughlin ${ }^{1}$ \\ From ESICM LIVES 2014 \\ Barcelona, Spain. 27 September - 1 October 2014
}

\begin{abstract}
Introduction
Acute lung injury (ALI) is a devastating clinical condition, characterised by acute inflammation that often proceeds to overt pulmonary fibrosis. Basal bone morphogenetic protein (BMP) signalling is essential for normal pulmonary homeostasis. The BMP antagonist gremlin has previously been shown to be increased in hypoxic lung disease, reduce BMP signalling and thus contribute directly to lung damage [1]. BMP antagonsists also play important roles in fibrotic diseases [2].
\end{abstract}

\section{Objectives}

The aim of this study was to investigate the expresison of BMP accessory proteins in an animal model of ALI and assess any associated changes in BMP signalling.

\section{Methods}

Acute lung injury was induced in adult mice by intratracheal instillation of bleomycin $(1 \mathrm{U} / \mathrm{kg})$; saline was instilled in control animals. Fourteen days post inoculation, animals were anaesthetised, killed and their lungs removed and snap frozen for later analysis of RNA and protein. Lungs from separate groups were isolated, fixed, and wax embedded for histological and immunohistochemical analysis.

\section{Results}

Bleomycin treated lungs showed characteristic structural changes and patchy inflammation. Gremlin, follistatin, follistatin like 1, follistatin like 3, BMPER and noggin mRNA expression was increased, the expression of BAMBI and NOV was reduced. MGP, KCP, lefty and chordin were unchanged. Expresion of Follistatin like 1, BAMBI and noggin protein was increased. Consistent with attentuated BMP signalling, BMP-2 and phospho-smad $1 / 5 / 8$ was reduced.

\section{Conclusions}

These data demonstrate that BMP antagonists are altered in bleomycin injured lungs and associated with reduced BMP signalling.

Grant acknowledgment

St Vincent's Anaesthesia Foundation, St. Vincent's University Hospital, Dublin 4, Ireland

\section{Authors' details}

${ }^{1}$ University College Dublin, School of Medicine and Medical Sciences, Dublin, Ireland. 'St Vincent's Hospital, Anaesthesia and Intensive Care Medicine, Dublin, Ireland. ${ }^{3}$ University college Dublin, School of Medicine and Medical Sciences, Dublin, Ireland. ${ }^{4}$ University College Dublin, School of Medicine and Medical Sciences, Dubiln, Ireland.

Published: 26 September 2014

\section{References}

1. Cahill E, Costello CM, Rowan SC, Harkin S, Howell K, Leonard MO, Southwood M, Cummins EP, Fitzpatrick SF, Taylor CT, Morrell NW, Martin F, Mcloughlin P: Gremlin plays a key role in the pathogenesis of pulmonary hypertension. Circulation 2012, 125:920-30.

2. Koli K, Myllarniemi M, Vuorinen K, Salmenkivi K, Ryynanen MJ, Kinnula VL, Keski-Oja J: Bone morphogenetic protein-4 inhibitor gremlin is overexpressed in idiopathic pulmonary fibrosis. The American journal of pathology 2006, 169:61-71.

doi:10.1186/2197-425X-2-S1-P64

Cite this article as: Murphy et al:: 0859. Altered expression of the bone morphogenetic antagonists in the bleomycin model of acute lung injury. Intensive Care Medicine Experimental 2014 2(Suppl 1):P64. 